\title{
Rapid quantification of fatty acids in plant oils and biological samples by LC-MS
}

\author{
Elisabeth Koch ${ }^{1} \cdot$ Michelle Wiebel $^{1} \cdot$ Carolin Hopmann $^{1} \cdot$ Nadja Kampschulte $^{1} \cdot$ Nils Helge Schebb $^{1}$
}

Received: 16 April 2021 / Revised: 21 June 2021 / Accepted: 1 July 2021 / Published online: 22 July 2021

(C) The Author(s) 2021

\begin{abstract}
Analysis of fatty acids (FA) in food and biological samples such as blood is indispensable in modern life sciences. We developed a rapid, sensitive and comprehensive method for the quantification of 41 saturated and unsaturated fatty acids by means of LCMS. Optimized chromatographic separation of isobaric analytes was carried out on a C8 reversed phase analytical column $(100 \times$ $2.1 \mathrm{~mm}, 2.6 \mu \mathrm{m}$ core-shell particle) with a total run time of 15 min with back pressure lower than 300 bar. On an old triple quadrupole instrument (3200, AB Sciex), pseudo selected reaction monitoring mode was used for quantification of the poorly fragmenting FA, yielding limits of detection of 5-100 nM. Sample preparation was carried out by removal of phospholipids and triglycerides by solid-phase extraction (non-esterified fatty acids in oils) or saponification in iso-propanol (fatty acyls). This is not only a rapid strategy for quantification of fatty acyls, but allows the direct combination with the LC-MS-based analysis of fatty acid oxidation products (eicosanoids and other oxylipins) from the same sample. The concentrations of fatty acyls determined by means of LC-MS were consistent with those from GC-FID analysis demonstrating the accuracy of the developed method. Moreover, the method shows high precisions with a low intra-day $(\leq 10 \%$ for almost all fatty acids in plasma and $\leq 15 \%$ in oils) and inter-day as well as inter-operator variability $(<20 \%)$. The method was successfully applied on human plasma and edible oils. The possibility to quantify non-esterified fatty acids in samples containing an excess of triacylglycerols and phospholipids is a major strength of the described approach allowing to gain new insights in the composition of biological samples.
\end{abstract}

Keywords Chromatographic separation $\cdot$ Pseudo-SRM $\cdot$ Non-esterified fatty acids $\cdot$ Saponification $\cdot$ Oxylipins

\section{Introduction}

Fatty acids play a fundamental role in the biology of living organisms, e.g., by influencing properties of biomembranes, storing and providing energy, or being involved in cell signaling [1-3]. Especially long-chain polyunsaturated fatty acids (PUFA) such as arachidonic acid (ARA), eicosapentaenoic acid (EPA) or docosahexaenoic acid (DHA) are involved in many (patho)physiological processes, i.a., through their oxidation products. These eicosanoids and other oxylipins are highly potent lipid mediators regulating for example inflammation, vasoconstriction or pain $[4,5]$. Dietary

Nils Helge Schebb

nils@schebb-web.de

1 Chair of Food Chemistry, Faculty of Mathematics and Natural Sciences, University of Wuppertal, Gaussstrasse 20,

42119 Wuppertal, Germany supplementation of n3-PUFAs or reducing the intake of n6PUFA is a promising way to modulate endogenous fatty acid distribution which has been demonstrated in numerous intervention studies [6-8].

The basic structure of fatty acids is a linear hydrocarbon chain with a varying number of double bonds. A large number of structurally similar molecules, e.g., n3- vs. n6-PUFA, leads to challenges in analytics. Fatty acyls are often analyzed by means of gas chromatography coupled to flame ionization detection (GC-FID) or mass spectrometry (GC-MS) due to the high separation efficiency and good sensitivity of GC [9-11]. However, transesterification or derivatization is necessary for this analytical procedure, which is on the one hand laborious and time-consuming and on the other hand can lead to discrimination of analytes [12]. Similarly, the need for derivatization makes quantifying non-esterified fatty acids (NEFA) in biological samples by GC challenging due to the high amount of fatty acyls occurring in different lipid classes such as triacylglycerols or phospholipids. Fractionation of 
these lipid classes by solid-phase extraction (SPE) is a powerful tool to separate NEFA from other lipid species [13]: However, already $1-2 \%$ of unremoved triacylglycerols or phospholipids disturbs the quantification of low abundant NEFA in biological samples and plant oils.

The use of liquid chromatography-mass spectrometry (LC-MS) has raised strong interest in fatty acid analysis in recent years. Even though some published methods include derivatization of the fatty acids, e.g., to improve ionization efficiency $[14,15]$, determination by LC-MS offers the possibility of analyzing fatty acids directly [16, 17]. Reversed phase columns based on modified silica gel are commonly used as stationary phase usually in combination with more non-polar solvents such as iso-propanol/acetonitrile mixtures [16, 18$]$.

However, none of the published LC-MS approaches [15, 16, 19-25] fulfills our needs regarding comprehensiveness, chromatographic separation of isobaric fatty acids, high sample throughput and applicability for a wide range of matrices. Therefore, we developed herein a new method which (i) covers a comprehensive set of biologically occurring fatty acids, (ii) allows rapid analysis ( $<15 \mathrm{~min}$ ) but separation of positional isomers, and (iii) requires only simple sample preparation by saponification following dilution in organic solvent. The latter allows us to analyze the oxidation products of fatty acids, eicosanoids and other oxylipins, from the same sample preparation using an established targeted oxylipin metabolomics method [26]. The method optimization and performance were characterized and compared to earlier published methods and the accuracy was demonstrated by crossvalidation with a standard GC-FID approach. Finally, the method was successfully applied to analyze human plasma and refined as well as virgin plant oils.

\section{Material and methods}

\section{Chemicals and biological materials}

Fatty acid standards (C6:0, C7:0, C8:0, C9:0, C10:0, C11:0, C12:0, C13:0, C15:0, C17:0, C18:2 n6, C18:1 n9, C18:0, C20:0, C21:0, C8:0-d15, C12:0-d23, and C20:5 n3-d5) were purchased from Merck (Darmstadt, Germany). The internal standards C16:0-d4 and C18:0-d5 were bought from Eurisotop (Saarbrücken, Germany). All other fatty acid standards were purchased from Cayman Chemicals (Ann Arbor, MI, USA). Fatty acid methyl ester (FAME) standards for the FAME reference mix were from Restek (marine fish oil mix; Bad Homburg vor der Höhe, Germany), Merck (FAME C22:4 n6, FAME C22:5 n3, FAME C25:0, Supelco 37 Component FAME Mix; Darmstadt, Germany), Fluka/ Honeywell (FAME C19:0; Offenbach, Germany), and Cayman Chemicals (FAME C18:4 n3, FAME C20:3 n9,
FAME C20:4 n3; Ann Arbor, MI, USA). The used edible oils (refined and virgin sunflower oil as well as virgin flaxseed oil) samples were bought in local supermarkets in Wuppertal, Germany. Pooled human EDTA plasma was generated from healthy individuals as described [26] in accordance with the guidelines of the Declaration of Helsinki and approved by the ethics committee of the University of Wuppertal. Acetonitrile $(\mathrm{ACN})$ and ethanol (EtOH) were obtained from VWR (Darmstadt, Germany) and methanol (MeOH), iso-propanol, as well as acetic acid (HAc) from Fisher Scientific (Schwerte, Germany). Ultra-pure water was generated using the Barnstead Genpure Pro system from Thermo Fisher Scientific (Langenselbold, Germany). All other chemicals were from Merck (Darmstadt, Germany).

\section{LC-ESI(-)-MS analysis}

Analysis was carried out on a 1260 Infinity LC System (Agilent, Waldbronn, Germany) coupled to a API 3200 instrument (AB Sciex, Darmstadt, Germany). Ionization was carried out in negative electrospray ionization $(\mathrm{ESI}(-))$ mode with the following source settings: ion spray voltage $-4500 \mathrm{~V}$, curtain gas (nitrogen, $\mathrm{N}_{2}$-generator NGM 33, cmc Instruments, Eschborn, Germany) 35 psi, nebulizer gas (gas 1, purified compressed air; "zero air") 70 psi generated with a RAMS 05ZA (cmc Instruments, Eschborn, Germany), drying gas (gas 2, purified compressed air) $55 \mathrm{psi}$, temperature $500{ }^{\circ} \mathrm{C}$. The sprayer offset was $0.511 \mathrm{~cm}$ for the vertical and $0.519 \mathrm{~cm}$ for the horizontal axis. The electrode protrusion was approximately $1 \mathrm{~mm}$. Ten microliters of samples were injected by an HTC PAL autosampler (CTC Analytics, Switzerland, local distributor: Axel Semrau, Sprockhövel, Germany) equipped with a $25-\mu 1$ syringe and a $20-\mu 1$ sample loop. Samples were cooled at $4{ }^{\circ} \mathrm{C}$. Separation of fatty acids was carried out on Kinetex C8 core-shell reversed phase column $(100 \times 2.1 \mathrm{~mm}$, particle size $2.6 \mu \mathrm{m}$, pore size $10 \mathrm{~nm}$; Phenomenex, Aschaffenburg, Germany) kept at $40{ }^{\circ} \mathrm{C}$. The analytical column was equipped with an inline filter $(0.3 \mu \mathrm{m}, 1290$ infinity II inline filter, Agilent, Waldbronn, Germany) and a SecurityGuard Ultra C8 cartridge as precolumn (2.1 mm ID, Phenomenex, Aschaffenburg, Germany). Solvent B of the mobile phase consisted of ACN/MeOH/HAc (80/15/0.1, v/v/ $v$ ) and solvent A was $0.1 \%$ HAc mixed with $5 \%$ of solvent B. The following linear gradient was used: $0.0-1.0 \mathrm{~min}$ isocratic $20 \% \mathrm{~B}, 1.0-1.5 \mathrm{~min}$ linear from $20 \% \mathrm{~B}$ to $66 \% \mathrm{~B}, 1.5-8.0 \mathrm{~min}$ isocratic $66 \% \mathrm{~B}, 8.0-11.0 \mathrm{~min}$ linear from $66 \% \mathrm{~B}$ to $100 \% \mathrm{~B}$, $11.0-14.0 \mathrm{~min}$ isocratic $100 \% \mathrm{~B}, 14.0-14.5 \mathrm{~min}$ linear from $100 \% \mathrm{~B}$ to $20 \% \mathrm{~B}$ followed by equilibration for $0.5 \mathrm{~min}$. This resulted in a total run time of $15 \mathrm{~min}$. The Analyst software (version 1.6.2, Sciex) was used for instrument control as well as data acquisition and Multiquant (version 2.1.1, Sciex) for peak integration and quantification. 


\section{Calibration and quantification}

Stock solutions of the individual fatty acids were mixed and diluted in EtOH using glass volumetric flasks to concentration levels of $0.05,0.075,0.1,0.25,0.5,0.75,1.0$, and $2.5 \mu \mathrm{M}$. For fatty acids which often occur in high concentrations in biological samples (C16:0, C16:1 n7, C18:0, C18:1 n9, C18:2 n6, $\mathrm{C} 20: 4 \mathrm{n} 6$ ) final concentration levels were $0.1,0.25,0.5,1.0$, $2.5,5.0,10.0,15.0$, and $20.0 \mu \mathrm{M}$. Concentrations of fatty acids in stock solution $(200 \mu \mathrm{M})$ were verified by GC-FID following $\mathrm{HCl}$-catalyzed transmethylation to fatty acid methyl esters (FAME) according to Ostermann et al. (see Supplementary Information (ESM) Fig. S1) [12]. If the determined concentration of a fatty acid in stock solution was not within $\pm 15 \%$, a correction factor was used. Additionally, the concentration of PUFAs in the calibration solution is monitored using a FAME reference mix to compensate for autoxidative degradation. The FAME reference mix was directly analyzed by GC-FID and prepared as sample for LCMS determination. If the PUFA concentration determined by GC-FID and LC-MS was not within $\pm 10 \%$, a second correction factor was used. C8:0-d15, C12:0-d23, C16:0-d4, C18:0d5, C18:1 n9-d17, C18:2 n6-d4, C20:0-d3, C20:3 n6-d6, $\mathrm{C} 20: 4 \mathrm{n} 6-\mathrm{d} 8, \mathrm{C} 20: 5 \mathrm{n} 3-\mathrm{d} 5$, and $\mathrm{C} 22: 6 \mathrm{n} 3-\mathrm{d} 5$ were used as internal standards at a concentration of $0.2 \mu \mathrm{M}$.

For calibration, the peak area ratios (analyte/IS) were plotted against the concentration ratio (analyte/IS). Calibration curves were calculated using linear or quadratic least square regression (weighting: $1 / x^{2}$, Table 1 ). The limit of detection (LOD) was determined by a signal-to-noise ratio of $\geq 3$ and the lower limit of quantification (LLOQ) by signal-to-noise ratio of $\geq 5$ and accuracy of $\pm 20 \%$ within the calibration curve. For fatty acids which are ubiquitously detectable in blank injection, i.e., injection of EtOH, the LLOQ was set to the concentration yielding a peak height of at least twofold of the peak height in blank injections and accuracy within the calibration curve of $\pm 20 \%$.

\section{Sample preparation}

For quantification of fatty acyl concentrations in oils, $4-5 \mathrm{mg}$ oil were diluted with $1.5 \mathrm{ml}$ iso-propanol. One hundred microliters of this solution were mixed with $300 \mu \mathrm{l}$ iso-propanol, $10 \mu \mathrm{l}$ of antioxidant mixture $(0.2 \mathrm{mg} / \mathrm{ml}$ butylated hydroxy toluene (BHT), $100 \mu \mathrm{M}$ indomethacin, $100 \mu \mathrm{M}$ trans-4-(4-(3-adamantan-1-yl-ureido)-cyclohexyloxy)-benzoic acid ( $t$ AUCB) in $\mathrm{MeOH}$ ), $50 \mu \mathrm{l}$ water and $100 \mu \mathrm{l} 0.6 \mathrm{M} \mathrm{KOH}$ in $\mathrm{MeOH} / \mathrm{H}_{2} \mathrm{O}(75 / 25, v / \mathrm{v})$. Samples were hydrolyzed (30 min, $60{ }^{\circ} \mathrm{C}$ ). Following neutralization with $20 \mu \mathrm{l} 25 \%$ HAc samples were diluted $(20 \mu \mathrm{l} / 500 \mu \mathrm{l})$ in EtOH and additionally $10 \mu \mathrm{l} / 100 \mu \mathrm{l}$ for high-concentrated fatty acids and $50 \mu \mathrm{l} /$ $100 \mu \mathrm{l}$ for low-concentrated fatty acids.
For quantification of fatty acyls in plasma, $100 \mu$ l plasma were mixed with $10 \mu \mathrm{l}$ antioxidant mixture and $400 \mu \mathrm{l}$ ice-cold iso-propanol. Following centrifugation $\left(4{ }^{\circ} \mathrm{C}\right.$, $20,000 \times \mathrm{g}, 10 \mathrm{~min}), 450 \mu \mathrm{l}$ of the supernatant were collected. For hydrolysis $\left(30 \mathrm{~min}, 60^{\circ} \mathrm{C}\right), 100 \mu \mathrm{l} 0.6 \mathrm{M} \mathrm{KOH}$ in $\mathrm{MeOH} / \mathrm{H}_{2} \mathrm{O}(75 / 25, \mathrm{v} / \mathrm{v})$ were added. After neutralization with $20 \mu \mathrm{l} 25 \%$ HAc samples were diluted $(20 \mu \mathrm{l} / 500 \mu \mathrm{l}$ and subsequently $50 \mu \mathrm{l} / 100 \mu \mathrm{l}$ ) in EtOH. Free fatty acids in plasma were analyzed in the same way without hydrolysis and the following dilution: $10 \mu \mathrm{l} / 100 \mu \mathrm{l}$ for highconcentrated fatty acids and $40 \mu 1 / 100 \mu 1$ for lowconcentrated fatty acids.

For quantification of NEFA in plant oils solid-phase extraction on aminopropyl columns ( $1 \mathrm{ml}$ volume, $100 \mathrm{mg}$ bed weight, Supelco/Merck, Darmstadt, Germany) was used to remove triacylglycerols [13]. Approximately $10 \mathrm{mg}$ of oils were diluted in $1 \mathrm{ml}$ chloroform/iso-propanol 2/1 $(v / v)$. Ten microliters of BHT $(0.02 \mathrm{mg} / \mathrm{ml}$ in $\mathrm{MeOH})$ and $10 \mu \mathrm{l} 20: 4 \mathrm{n} 6$ $(160 \mu \mathrm{M})$ as internal standard were added. The columns were washed with two cartridge volumes of diethyl ether/HAc 98/2 $(v / v)$ and two cartridge volumes of chloroform/iso-propanol 2/1 $(v / v)$. Samples were loaded onto the cartridges and triacylglycerols were removed with two cartridge volumes of chloroform/ iso-propanol 2/1 $(v / v)$. NEFA were eluted with two cartridge volumes of diethyl ether/HAc 98/2 (v/v). The eluate was neutralized with $1 \mathrm{ml} 1 \mathrm{M} \mathrm{NaHCO}_{3}$, and the upper layer was collected and evaporated to dryness (vacuum concentrator, $30{ }^{\circ} \mathrm{C}, 1$ mbar; Christ, Osterode, Germany). The residue was reconstituted in $200 \mu \mathrm{l} \mathrm{EtOH}$, diluted $50 \mu \mathrm{l} / 100 \mu \mathrm{l}$ for lowconcentrated fatty acids as well as $10 \mu \mathrm{l} / 100 \mu \mathrm{l}$ and subsequently $40 \mu \mathrm{l} / 100 \mu \mathrm{l}$ for high-concentrated fatty acids.

\section{Results and discussion}

A sensitive and selective quantification of fatty acids by means of LC-MS was developed: mass spectrometric detection was optimized and a rapid, efficient chromatographic separation was developed. The method performance was characterized and the results were compared with those from GCFID analysis. Finally, the method was applied to the analysis of fatty acyls as well as NEFA in plasma and in plant oils.

\section{Optimization of mass spectrometric detection}

Fatty acids contain a carboxy group; thus, ionization was carried out in $\operatorname{ESI}(-)$ mode. This leads to the formation of $[\mathrm{M}-\mathrm{H}]^{-}$ ions which where the dominating ions detected in MS fullscan experiments. The declustering potential was optimized in single ion monitoring mode of the $[\mathrm{M}-\mathrm{H}]^{-}$ions for each fatty acid (Table 1). Monitoring of collision-induced dissociation (CID) fragment spectra revealed no fragmentation for fatty acids with $\leq 3$ double bonds, while for PUFA with $\geq 4$ double 
Table 1 LC-ESI(-)-MS/MS parameters and performance for the quantification of fatty acids. Shown are all fatty acids covered by the method, their mass transitions for quantification in scheduled SRM mode, specific electronic MS parameters (declustering potential (DP), collision energy (CE)), their internal standards (IS), retention time $\left(t_{\mathrm{R}}\right)$, full peak width at half maximum (FWHM), the calibration range, the limit of detection (LOD) and the lower limit of quantification (LLOQ). Scheduled selected reaction monitoring mode (SRM) using nitrogen as collision gas (12 psi) with a detection window of $\pm 35 \mathrm{~s}$ around the expected retention time was used for analyte detection

\begin{tabular}{|c|c|c|c|c|c|c|c|c|c|c|c|c|c|}
\hline \multirow[t]{2}{*}{ Analyte } & \multicolumn{2}{|c|}{ Mass transition } & \multicolumn{2}{|c|}{ Electronic parameters } & \multirow[t]{2}{*}{ Internal standard } & \multirow{2}{*}{$\begin{array}{l}t_{\mathrm{R}}^{\mathrm{a}} \\
(\mathrm{min})\end{array}$} & \multirow{2}{*}{$\begin{array}{l}\text { FWHM } \\
\text { (s) }\end{array}$} & \multicolumn{3}{|c|}{ Calibration range } & \multicolumn{2}{|l|}{ LOD } & \multirow{2}{*}{$\begin{array}{l}\text { LLOQ } \\
(\mu \mathrm{M})\end{array}$} \\
\hline & Q1 & Q3 & $\begin{array}{l}\text { DP } \\
(\mathbf{v})\end{array}$ & $\mathbf{C E}$ & & & & \multicolumn{3}{|l|}{$(\mu \mathbf{M})$} & $(\mu \mathbf{M})$ & ng in column & \\
\hline C6:0 & 115.2 & 115.2 & -24 & -14 & C8:0-d15 & $2.81 \pm 0.01$ & $3.4 \pm 0.1$ & 0.1 & - & 2.5 & $-^{\mathrm{c}}$ & $-^{\mathrm{c}}$ & $0.1^{\mathrm{e}}$ \\
\hline C7:0 & 129.2 & 129.2 & -42 & -10 & C8:0-d15 & $3.05 \pm 0.01$ & $3.2 \pm 0.1$ & 0.075 & - & 2.5 & $-^{\mathrm{c}}$ & $-^{\mathrm{c}}$ & $0.075^{\mathrm{e}}$ \\
\hline C8:0 & 143.2 & 143.2 & -32 & -10 & C8:0-d15 & $3.30 \pm 0.01$ & $3.2 \pm 0.2$ & 0.1 & - & 2.5 & $-^{\mathrm{c}}$ & $-^{\mathrm{c}}$ & $0.1^{\mathrm{e}}$ \\
\hline C9:0 & 157.1 & 157.1 & -42 & -14 & C8:0-d15 & $3.61 \pm 0.01$ & $3.3 \pm 0.1$ & $-^{\mathrm{d}}$ & & - & $-^{\mathrm{c}}$ & $-^{\mathrm{c}}$ & $-{ }^{\mathrm{d}}$ \\
\hline $\mathrm{C} 10: 0$ & 171.2 & 171.2 & -44 & -14 & C8:0-d15 & $4.01 \pm 0.01$ & $3.5 \pm 0.2$ & 0.05 & - & 2.5 & $-^{\mathrm{c}}$ & $-^{\mathrm{c}}$ & $0.05^{\mathrm{e}}$ \\
\hline C11:0 & 185.1 & 185.1 & -36 & -16 & $\mathrm{C} 12: 0-\mathrm{d} 23$ & $4.52 \pm 0.01$ & $3.8 \pm 0.1$ & 0.05 & - & 2.5 & $-^{\mathrm{c}}$ & $-^{\mathrm{c}}$ & $0.05^{\mathrm{e}}$ \\
\hline $\mathrm{C} 12: 0$ & 199.1 & 199.1 & -44 & -14 & $\mathrm{C} 12: 0-\mathrm{d} 23$ & $5.19 \pm 0.02$ & $4.5 \pm 0.2$ & 0.1 & - & 2.5 & $-^{\mathrm{c}}$ & $-^{\mathrm{c}}$ & $0.1^{\mathrm{e}}$ \\
\hline $\mathrm{C} 13: 0$ & 213.2 & 213.2 & -46 & -16 & $\mathrm{C} 12: 0-\mathrm{d} 23$ & $6.10 \pm 0.03$ & $5.8 \pm 0.3$ & 0.05 & - & 2.5 & 0.005 & 0.01 & 0.01 \\
\hline C14:1 n5 & 225.2 & 225.2 & -46 & -16 & $\mathrm{C} 12: 0-\mathrm{d} 23$ & $5.74 \pm 0.03$ & $5.3 \pm 0.2$ & 0.05 & - & 2.5 & 0.005 & 0.01 & 0.01 \\
\hline C14:0 & 227.1 & 227.1 & -46 & -14 & $\mathrm{C} 12: 0-\mathrm{d} 23$ & $7.32 \pm 0.04$ & $7.7 \pm 0.5$ & 0.075 & - & 2.5 & $-^{\mathrm{c}}$ & $-^{\mathrm{c}}$ & $0.075^{\mathrm{e}}$ \\
\hline C15:1 n5 & 239.2 & 239.2 & -36 & -14 & $\mathrm{C} 12: 0-\mathrm{d} 23$ & $6.79 \pm 0.04$ & $7.0 \pm 0.3$ & 0.05 & - & 2.5 & 0.006 & 0.01 & 0.012 \\
\hline $\mathrm{C} 15: 0$ & 241.3 & 241.3 & -44 & -14 & $\mathrm{C} 12: 0-\mathrm{d} 23$ & $9.00 \pm 0.06$ & $11.4 \pm 0.6$ & 0.05 & - & 2.5 & 0.01 & 0.02 & 0.025 \\
\hline $\mathrm{C} 16: 1 \mathrm{n} 7$ & 253.3 & 253.3 & -48 & -20 & C18:1 n9-d17 & $8.28 \pm 0.05$ & $9.4 \pm 0.4$ & 0.1 & - & 20 & 0.005 & 0.01 & 0.01 \\
\hline $\mathrm{C} 16: 0$ & 255.2 & 255.2 & -44 & -20 & C16:0-d4 & $10.38 \pm 0.03$ & $6.8 \pm 0.4$ & 0.5 & - & 20 & $-^{\mathrm{c}}$ & $-^{\mathrm{c}}$ & $0.5^{\mathrm{e}}$ \\
\hline $\mathrm{C} 17: 0$ & 269.3 & 269.3 & -48 & -20 & $\mathrm{C} 20: 0-\mathrm{d} 3$ & $11.03 \pm 0.02$ & $4.1 \pm 0.3$ & 0.05 & - & 2.5 & 0.005 & 0.01 & 0.01 \\
\hline C18:4 n3 & 275.3 & 275.3 & -36 & -16 & $\mathrm{C} 20: 5 \mathrm{n} 3-\mathrm{d} 5^{\mathrm{f}}$ & $6.25 \pm 0.03$ & $6.0 \pm 0.2$ & 0.05 & - & 2.5 & 0.01 & 0.03 & 0.025 \\
\hline & 275.3 & 231.3 & -36 & -16 & & $6.25 \pm 0.03$ & $5.9 \pm 0.5$ & 0.075 & - & 2.5 & 0.05 & 0.1 & 0.075 \\
\hline C18:3 n6 & 277.2 & 277.2 & -46 & -22 & $\mathrm{C} 20: 5 \mathrm{n} 3-\mathrm{d} 5$ & $7.75 \pm 0.05$ & $8.3 \pm 0.6$ & 0.05 & - & 2.5 & 0.025 & 0.07 & 0.05 \\
\hline $\mathrm{C} 18: 3 \mathrm{n} 3$ & 277.2 & 277.2 & -44 & -24 & $\mathrm{C} 20: 5 \mathrm{n} 3-\mathrm{d} 5$ & $7.46 \pm 0.04$ & $7.9 \pm 0.4$ & 0.05 & - & 2.5 & 0.025 & 0.07 & 0.05 \\
\hline C18:2 n6 & 279.3 & 279.3 & -46 & -16 & C18:2 n6-d4 & $9.52 \pm 0.06$ & $9.6 \pm 0.3$ & 0.1 & - & 15 & $-^{\mathrm{c}}$ & $-^{\mathrm{c}}$ & $0.01^{\mathrm{e}}$ \\
\hline C18:1 n9 & 281.4 & 281.4 & -46 & -18 & C18:1 n9-d17 & $10.80 \pm 0.02$ & $4.7 \pm 0.2$ & 0.1 & - & $15^{\mathrm{g}}$ & $-^{\mathrm{c}}$ & $-^{\mathrm{c}}$ & $0.05^{\mathrm{e}}$ \\
\hline $\mathrm{C} 18: 0$ & 283.2 & 283.2 & -46 & -20 & C18:0-d5 & $11.47 \pm 0.01$ & $5.5 \pm 0.5$ & 1 & - & 20 & $-^{\mathrm{c}}$ & $-^{\mathrm{c}}$ & $1.0^{\mathrm{e}}$ \\
\hline C19:0 & 297.4 & 297.4 & -46 & -20 & $\mathrm{C} 20: 0-\mathrm{d} 3$ & $11.79 \pm 0.01$ & $3.4 \pm 0.3$ & 0.05 & - & 2.5 & 0.005 & 0.01 & 0.01 \\
\hline $\mathrm{C} 20: 5 \mathrm{n} 3$ & 301.2 & 301.2 & -46 & -16 & $\mathrm{C} 20: 5 \mathrm{n} 3-\mathrm{d} 5^{\mathrm{f}}$ & $7.43 \pm 0.05$ & $7.8 \pm 0.4$ & 0.05 & - & 2.5 & 0.025 & 0.08 & 0.05 \\
\hline & 301.2 & 257.2 & -46 & -16 & & $7.43 \pm 0.05$ & $7.6 \pm 0.6$ & 0.075 & - & 2.5 & 0.05 & 0.2 & 0.075 \\
\hline C20:4 n6 & 303.2 & 303.2 & -46 & -18 & $\mathrm{C} 20: 4 \mathrm{n} 6-\mathrm{d} 8^{\mathrm{f}}$ & $9.43 \pm 0.06$ & $9.8 \pm 0.5$ & 0.1 & - & 20 & 0.02 & 0.06 & 0.05 \\
\hline & 303.2 & 259.2 & -46 & -18 & & $9.43 \pm 0.06$ & $9.1 \pm 0.9$ & 0.1 & - & 20 & 0.05 & 0.2 & 0.1 \\
\hline $\mathrm{C} 20: 4 \mathrm{n} 3$ & 303.3 & 303.3 & -46 & -18 & $\mathrm{C} 20: 5 \mathrm{n} 3-\mathrm{d} 5^{\mathrm{f}}$ & $8.74 \pm 0.06$ & $10.0 \pm 0.5$ & 0.05 & - & 2.5 & 0.01 & 0.03 & 0.025 \\
\hline & 303.3 & 259.2 & -46 & -18 & & $8.75 \pm 0.05$ & $9.4 \pm 1.0$ & 0.075 & - & 2.5 & 0.05 & 0.2 & 0.075 \\
\hline $\mathrm{C} 20: 3 \mathrm{n} 9$ & 305.4 & 305.4 & -46 & -14 & $\mathrm{C} 22: 6$ n3-d5 & $10.69 \pm 0.02$ & $4.5 \pm 0.1$ & 0.05 & - & 2.5 & 0.006 & 0.02 & 0.013 \\
\hline C20:3 n6 & 305.4 & 305.4 & -46 & -14 & C20:3 n6-d6 & $10.37 \pm 0.03$ & $5.5 \pm 0.1$ & 0.05 & - & 2.5 & 0.005 & 0.02 & 0.01 \\
\hline $\mathrm{C} 20: 2 \mathrm{n} 6$ & 307.3 & 307.3 & -48 & -24 & $\mathrm{C} 22: 6 \mathrm{n} 3-\mathrm{d} 5$ & $11.09 \pm 0.02$ & $4.0 \pm 0.2$ & 0.05 & - & 2.5 & 0.005 & 0.02 & 0.01 \\
\hline C20:1 n9 & 309.4 & 309.4 & -48 & -16 & $\mathrm{C} 20: 0-\mathrm{d} 3$ & $11.62 \pm 0.01$ & $3.4 \pm 0.2$ & 0.05 & - & 2.5 & 0.01 & 0.03 & 0.025 \\
\hline $\mathrm{C} 20: 0$ & 311.2 & 311.2 & -44 & -20 & $\mathrm{C} 20: 0-\mathrm{d} 3$ & $12.04 \pm 0.01$ & $3.5 \pm 0.2$ & 0.05 & - & 2.5 & $-^{\mathrm{c}}$ & $-^{\mathrm{c}}$ & $0.05^{\mathrm{e}}$ \\
\hline $\mathrm{C} 21: 0$ & 325.2 & 325.2 & -48 & -16 & $\mathrm{C} 20: 0-\mathrm{d} 3$ & $12.25 \pm 0.01$ & $3.3 \pm 0.4$ & 0.075 & - & 2.5 & 0.05 & 0.2 & 0.075 \\
\hline $\mathrm{C} 22: 6 \mathrm{n} 3$ & 327.4 & 327.4 & -46 & -16 & $\mathrm{C} 22: 6 \mathrm{n} 3-\mathrm{d} 5^{\mathrm{f}}$ & $9.09 \pm 0.06$ & $10.2 \pm 0.6$ & 0.05 & - & 2.5 & 0.025 & 0.08 & 0.05 \\
\hline & 327.4 & 283.4 & -46 & -16 & & $9.09 \pm 0.07$ & $9.3 \pm 0.8$ & 0.075 & - & 2.5 & 0.05 & 0.2 & 0.075 \\
\hline $\mathrm{C} 22: 5 \mathrm{n} 6$ & 329.2 & 329.2 & -48 & -20 & $\mathrm{C} 22: 6 \mathrm{n} 3-\mathrm{d} 5^{\mathrm{f}}$ & $10.49 \pm 0.02$ & $4.9 \pm 0.2$ & 0.05 & - & 2.5 & 0.01 & 0.03 & 0.025 \\
\hline & 329.5 & 285.2 & -48 & -20 & & $10.49 \pm 0.02$ & $4.8 \pm 0.4$ & 0.05 & - & 2.5 & 0.025 & 0.08 & 0.05 \\
\hline $\mathrm{C} 22: 5 \mathrm{n} 3$ & 329.2 & 329.2 & -48 & -20 & $\mathrm{C} 22: 6 \mathrm{n} 3-\mathrm{d} 5^{\mathrm{f}}$ & $10.02 \pm 0.03$ & $6.3 \pm 0.2$ & 0.05 & - & 2.5 & 0.01 & 0.03 & 0.025 \\
\hline & 329.2 & 285.2 & -48 & -20 & & $10.02 \pm 0.04$ & $6.3 \pm 0.6$ & 0.075 & - & 2.5 & 0.05 & 0.2 & 0.075 \\
\hline $\mathrm{C} 22: 4 \mathrm{n} 6$ & 331.3 & 331.3 & -40 & -20 & $\mathrm{C} 22: 6 \mathrm{n} 3-\mathrm{d} 5^{\mathrm{f}}$ & $10.88 \pm 0.02$ & $4.1 \pm 0.1$ & 0.05 & - & 2.5 & 0.005 & 0.02 & 0.01 \\
\hline & 331.3 & 287.3 & -40 & -20 & & $10.88 \pm 0.02$ & $4.1 \pm 0.3$ & 0.075 & - & 2.5 & 0.05 & 0.2 & 0.075 \\
\hline $\mathrm{C} 22: 2 \mathrm{n} 6$ & 335.3 & 335.3 & -46 & -20 & $\mathrm{C} 22: 6 \mathrm{n} 3-\mathrm{d} 5$ & $11.76 \pm 0.01$ & $3.2 \pm 0.3$ & 0.05 & - & 1 & 0.01 & 0.03 & 0.025 \\
\hline $\mathrm{C} 22: 1 \mathrm{n} 9$ & 337.5 & 337.5 & -46 & -26 & $\mathrm{C} 20: 0-\mathrm{d} 3$ & $12.11 \pm 0.01$ & $3.1 \pm 0.8$ & 0.05 & - & 2.5 & 0.025 & 0.08 & 0.05 \\
\hline $\mathrm{C} 22: 0$ & 339.2 & 339.2 & -46 & -20 & $\mathrm{C} 20: 0-\mathrm{d} 3$ & $12.45 \pm 0.01$ & $3.3 \pm 0.6$ & 0.075 & - & 2.5 & 0.05 & 0.2 & 0.075 \\
\hline $\mathrm{C} 23: 0$ & 353.2 & 353.2 & -48 & -16 & $\mathrm{C} 20: 0-\mathrm{d} 3$ & $12.65 \pm 0.01$ & $4.4 \pm 0.8$ & 0.075 & - & 1.0 & 0.05 & 0.2 & 0.075 \\
\hline $\mathrm{C} 24: 1 \mathrm{n} 9$ & 365.4 & 365.4 & -48 & -20 & $\mathrm{C} 20: 0-\mathrm{d} 3$ & $12.51 \pm 0.01$ & $4.0 \pm 0.5$ & 0.075 & - & 1.0 & 0.05 & 0.2 & 0.075 \\
\hline $\mathrm{C} 24: 0$ & 367.4 & 367.4 & -46 & -20 & $\mathrm{C} 20: 0-\mathrm{d} 3$ & $12.84 \pm 0.01$ & $4.8 \pm 0.9$ & 0.25 & - & 2.5 & 0.1 & 0.4 & 0.25 \\
\hline Internal standar & rds & & & & & & & & & & & & \\
\hline C8:0-d15 & 158.2 & 158.2 & -26 & -9 & IS & $3.28 \pm 0.01$ & $3.14 \pm 0.1$ & & & & & & \\
\hline $\mathrm{C} 12: 0-\mathrm{d} 23$ & 222.2 & 222.2 & -44 & -18 & IS & $5.08 \pm 0.02$ & $4.4 \pm 0.2$ & & & & & & \\
\hline $\mathrm{C} 16: 0-\mathrm{d} 4$ & 259.2 & 259.2 & -46 & -21 & IS & $10.35 \pm 0.03$ & $6.4 \pm 0.4$ & & & & & & \\
\hline C18:2 n6-d4 & 283.2 & 283.2 & -52 & -20 & IS & $9.45 \pm 0.06$ & $10.4 \pm 0.6$ & & & & & & \\
\hline C18:1 n9-d17 & 298.2 & 298.2 & -52 & -20 & IS & $10.72 \pm 0.02$ & $4.2 \pm 0.2$ & & & & & & \\
\hline $\mathrm{C} 18: 0-\mathrm{d} 5$ & 288.2 & 288.2 & -48 & -21 & IS & $11.44 \pm 0.01$ & $3.4 \pm 0.3$ & & & & & & \\
\hline $\mathrm{C} 20: 5 \mathrm{n} 3-\mathrm{d} 5$ & 306.2 & 306.2 & -44 & -20 & IS & $7.38 \pm 0.04$ & $7.4 \pm 0.6$ & & & & & & \\
\hline
\end{tabular}


Table 1 (continued)

\begin{tabular}{|c|c|c|c|c|c|c|c|c|c|c|}
\hline \multirow[t]{2}{*}{ Analyte } & \multicolumn{2}{|c|}{ Mass transition } & \multicolumn{2}{|c|}{ Electronic parameters } & \multirow[t]{2}{*}{ Internal standard } & \multirow{2}{*}{$\begin{array}{l}t_{\mathrm{R}}^{\mathrm{a}} \\
(\mathrm{min})\end{array}$} & \multirow{2}{*}{$\begin{array}{l}\text { FWHM }^{\mathbf{b}} \\
\text { (s) }\end{array}$} & \multirow{2}{*}{$\frac{\text { Calibration range }}{(\mu \mathrm{M})}$} & LOD & \multirow{2}{*}{$\begin{array}{l}\text { LLOQ } \\
(\mu \mathrm{M})\end{array}$} \\
\hline & Q1 & Q3 & $\begin{array}{l}\text { DP } \\
\text { (v) }\end{array}$ & $\mathbf{C E}$ & & & & & $(\mu \mathrm{M})$ ng in column & \\
\hline & 306.2 & 262.2 & -44 & -20 & & $7.38 \pm 0.04$ & $6.6 \pm 0.9$ & & & \\
\hline \multirow[t]{2}{*}{$\mathrm{C} 20: 4 \mathrm{n} 6-\mathrm{d} 8$} & 311.2 & 311.2 & -48 & -20 & IS & $9.29 \pm 0.06$ & $9.3 \pm 0.4$ & & & \\
\hline & 311.2 & 267.2 & -48 & -22 & & $9.28 \pm 0.06$ & $8.2 \pm 1.7$ & & & \\
\hline $\mathrm{C} 20: 3 \mathrm{n} 6-\mathrm{d} 6$ & 311.5 & 311.5 & -46 & -17 & IS & $10.32 \pm 0.03$ & $5.3 \pm 0.3$ & & & \\
\hline $\mathrm{C} 20: 0-\mathrm{d} 3$ & 314.2 & 314.2 & -50 & -21 & IS & $12.03 \pm 0.01$ & $3.6 \pm 0.3$ & & & \\
\hline \multirow[t]{2}{*}{$\mathrm{C} 22: 6 \mathrm{n} 3-\mathrm{d} 5$} & 332.5 & 332.5 & -42 & -20 & IS & $9.01 \pm 0.06$ & $10.0 \pm 0.8$ & & & \\
\hline & 332.5 & 288.2 & -42 & -24 & & $9.01 \pm 0.06$ & $9.5 \pm 1.3$ & & & \\
\hline
\end{tabular}

${ }^{\mathrm{a}}$ Mean $\pm \mathrm{SD}$ of the retention time in three different batches

${ }^{\mathrm{b}}$ Mean $\pm \mathrm{SD}$ of the full width at half maximum (FWHM) in three different batches

${ }^{\mathrm{c}}$ No LOD can be determined because analyte is also detectable in blank injection

${ }^{\mathrm{d}}$ No calibration possible due to high background levels

${ }^{\mathrm{e}}$ Determined by at least $2 \times$ peak height of blank injection and accuracy of $80-120 \%$

${ }^{\mathrm{f}}$ For quantification of fatty acid using the transition based on decarboxylation, the [M-H-44] $]^{-}$transition of the IS was used

${ }^{\mathrm{g}}$ Quadratic regression

bonds the formation of $[\mathrm{M}-\mathrm{H}-44]^{-}$ions was observed, resulting from a decarboxylation (Fig. 1). The lack of detection of fragments of the linear hydrocarbon backbone is consistent with earlier reports [20]. Interestingly, for n6-PUFA, the intensity of the fragment resulted from $\mathrm{CO}_{2}$ loss was higher compared to n3-PUFA which might be due to the spatial proximity of the double bonds to the carboxyl group in n6PUFA. This may lead to a higher fragmentation rate through stabilization of the fragment ion charge in the unsaturated carbon chain. Pseudo scheduled selected reaction monitoring mode (pseudo-SRM), i.e., isolating the $\mathrm{m} / z$ of $[\mathrm{M}-\mathrm{H}]^{-}$ions in Q1 and Q3, was used for quantification of fatty acids which do not show fragment ions in CID. Using the highest collision energy which did not lead to a decrease of the $[\mathrm{M}-\mathrm{H}]^{-}$ion in pseudo-SRM mode, co-eluting isobaric matrix is likely to be fragmented which increases the specificity of the detection. PUFA bearing $\geq 4$ double bonds were detected in pseudoSRM and additionally in regular SRM mode by using transition of the loss of $\mathrm{CO}_{2}$. However, because pseudo-SRM and decarboxylation are rather unspecific, chromatographic separation is crucial for isomeric fatty acids. The following critical isobaric separation pairs were identified among the biological occurring PUFA: C18:3 n3 (ALA) and n6 (GLA), C20:3 n6 (DGLA) and n9, C20:4 n3 (n3-ARA) and n6 (ARA), as well as C22:5 n3 (n3-DPA) and n6 (n6-DPA).

\section{Optimization of chromatographic separation}

Liquid chromatographic separation of low to moderately polar substances, including fatty acids, is commonly achieved using a C18 column [16, 20, 21, 27]. Using a state-of-the-art sub$2 \mu \mathrm{m}$ particle filled C18 reversed phase column (column 1;
Zorbax Eclipse Plus, $150 \times 2.1 \mathrm{~mm}$, Agilent, Waldbronn, Germany) and a linear $\mathrm{H}_{2} \mathrm{O} / \mathrm{MeOH} / \mathrm{ACN}$ gradient (Table 2), retention times of fatty acids were unacceptably long. Even using an optimized gradient with a long isocratic step (11 min) at $100 \% \mathrm{~B}$, long-chain fatty acids eluted at late retention times (C24:0 $20.28 \mathrm{~min}$ ). Moreover, ALA and GLA were not separated $(R=0.87)$. Different columns with lower hydrophobicity were tested aiming to increase the selectivity to separate isomers. ALA and GLA were the most critical separation pair; thus, a gradient was chosen yielding an optimal retention factor $(k)$ and an isocratic step at their retention time (Table 2): In order to adjust the appropriate elution power (percentage B) for the isocratic step, it was calculated from the linear starting gradient at which \%B ALA elutes and the isocratic step was set to this calculated percentage B minus $5 \%$.

With a biphenyl stationary phase (column 2; Nucleoshell, $150 \times 2.0 \mathrm{~mm}, 2.7 \mu \mathrm{m}$ particle size (core-shell), MachereyNagel, Düren, Germany) sufficient separation of ALA and GLA $(R=0.88)$ could not be achieved. It seems that the $\pi-\pi$ interactions between the isolated double bonds of the fatty acids and the aromatic double bonds of the biphenyl phase do not provide sufficient selectivity. This is supported by the results from a second biphenyl phase (Raptor Biphenyl, $100 \times$ $2.1 \mathrm{~mm}, 2.7 \mu \mathrm{m}$ core-shell particle), Restek, Bad Homburg vor der Höhe, Germany). On this column with a considerably lower hydrophobicity, a separation of ALA and GLA was not possible $(R=0.95)$, despite the shorter length comparable to that of column 2. Modification of the aromatic ring structure to pentafluorophenyl residues (column 3; PFP Kinetex, $100 \times$ $2.1 \mathrm{~mm}, 2.6 \mu \mathrm{m}$ core-shell particle) or linkage of a phenyl moiety to the silica gel via an ether bridge (column 4; Synergi Polar-RP, $100 \times 2.0 \mathrm{~mm}, 2.5 \mu \mathrm{m}$ particle size, both 

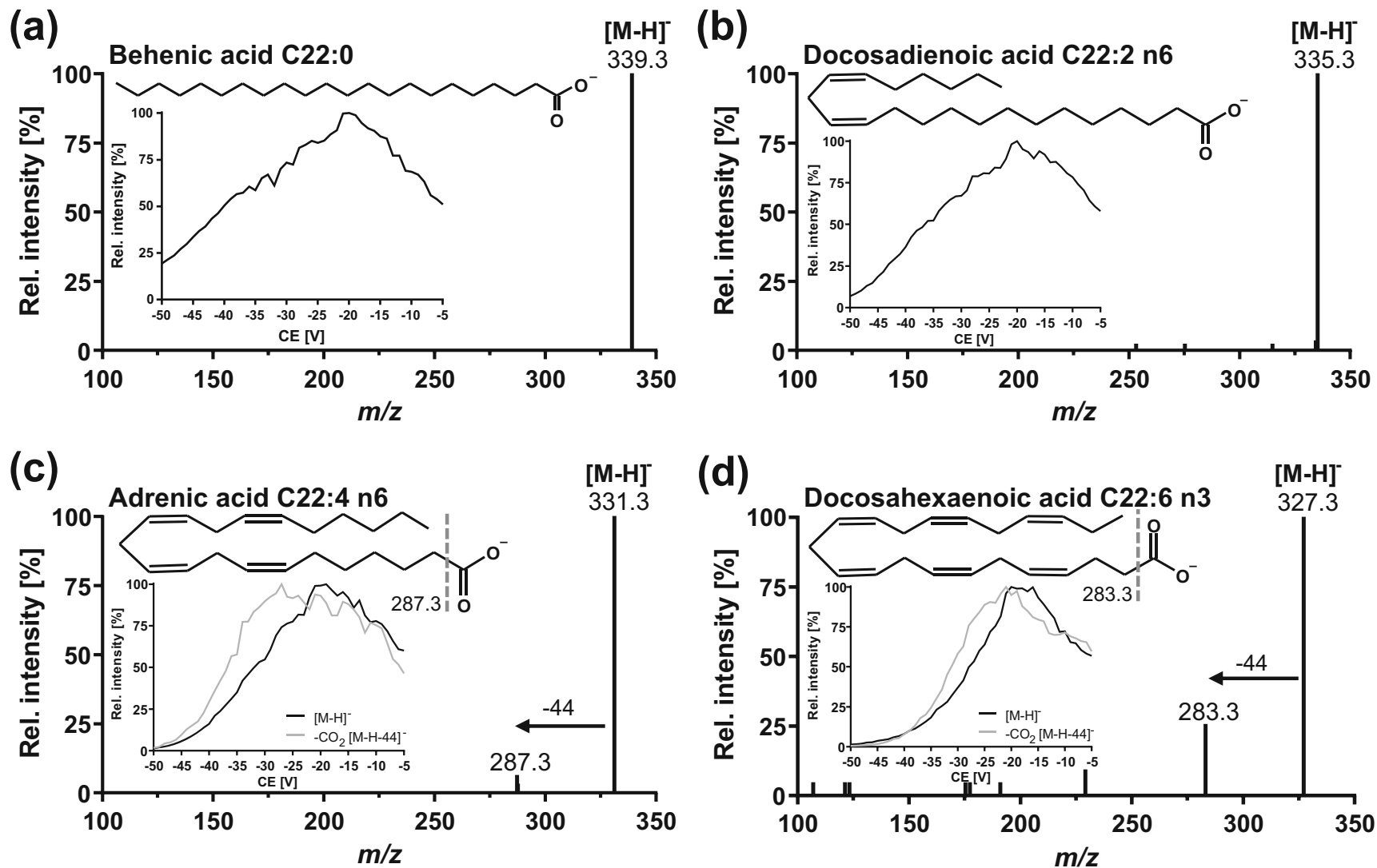

Fig. 1 Collision-induced dissociation (CID) product spectra of $[\mathrm{M}-\mathrm{H}]^{-}$ ions of selected fatty acids with 22 carbon atoms and increasing number of double bounds. a Behenic acid, $\mathbf{b}$ docosadienoic acid, $\mathbf{c}$ adrenic acid,

Phenomenex, Aschaffenburg, Germany) led to poor separation of ALA and GLA ( $R=0.65$ and 0.46 , respectively).

A baseline separation of ALA and GLA $(R>1.5)$ could be achieved on a $\mathrm{C} 8$ reversed phase column with dimensions of $100 \times 2.1 \mathrm{~mm}, 2.6 \mu \mathrm{m}$ core-shell particle (Kinetex, Phenomenex, Aschaffenburg, Germany). Increasing the hydrophobicity by ethyl-bridged hybrid silica (column 5, Triart, $100 \times 2.0 \mathrm{~mm}, 1.9 \mu \mathrm{m}$ particle size, YMC, Dinslaken, Germany) failed to further improve the separation $\left(R_{\mathrm{ALA}}\right.$ / $\mathrm{GLA}=1.25$ ).

With the optimized chromatographic conditions on the Kinetex C8 column, 41 fatty acids and 11 internal standards could be separated within $13.5 \mathrm{~min}$ (Fig. 2, ESM Fig. S2). The saturated fatty acids eluted over the entire run time, while the retention times for unsaturated fatty acids depended on the number of double bonds (Fig. 2). $\mathrm{Hu}$ et al. and Bromke et al. also described a pronounced relationship between retention time, number of carbon atoms, and number of double bonds [20, 21]. C24:0 eluted last with a retention time of $12.96 \mathrm{~min}$. In order to remove potentially retained non-polar matrix the isocratic step at $100 \%$ B was held for one void volume $(0.24 \mathrm{ml}, 0.8 \mathrm{~min})$. Including re-equilibration the final run time was $15 \mathrm{~min}$ with highly stable retention times showing a variation (relative standard deviation, RSD) of $<0.20 \%$

and $\mathbf{d}$ docosahexaenoic acid. Insert: Optimization of collision energy (CE) for pseudo-SRM and decarboxylation. Ionization was carried out in negative electrospray ionization mode

or $<0.02 \mathrm{~min}$ for intra-batch $(n=24)$ and $<0.75 \%$ or $<0.07$ min for inter-batch (three batches, $n=30$; Table 1).

Regarding the start conditions of the gradient, it turned out that a pre-concentration step [28] with low elution power $(20 \% \mathrm{~B})$ is required for a good separation of early eluting fatty acids. The lipophilic nature of fatty acids makes the use of the more non-polar injections solvent EtOH necessary; otherwise, long-chain fatty acids are discriminated (ESM Fig. S3). Without the pre-concentration step, the strong elution power of the injection solvent deteriorates the peak shape of the early eluting analytes (Fig. 3). With a retention factor $k>1$, the analytes are well separated from void volume $(k=2.36$ for C6; Table 2) using 20\% B for the initial step. ALA and GLA are separated by a long isocratic step at $66 \%$ B (6.5 $\min , R=1.88$ ), other critical separation pairs such as $\mathrm{n} 3$ - and n6-DPA were separated within a linear solvent gradient. Interestingly, while $\mathrm{C} 20: 3 \mathrm{n} 9$ and $\mathrm{n} 6$ were easily separable $(R=2.89), \mathrm{C} 20: 3 \mathrm{n} 6$ and $\mathrm{n} 3$ as well as $\mathrm{C} 18: 1 \mathrm{n} 9$ and $\mathrm{n} 7$ could not be separated on any of the tested columns. It is consistent with literature that RP-LC does not allow to separate $\mathrm{C} 20: 3 \mathrm{n} 6$ and $\mathrm{n} 3[16,22]$. However, in our experience, $\mathrm{C} 20: 3 \mathrm{n} 3$ and $\mathrm{C} 18: 1 \mathrm{n} 7$ do not occur or only occur at low concentrations in biological samples [7, 10, 29]. Thus, the quantification of $\mathrm{C} 20: 3 \mathrm{n} 6$ and $\mathrm{C} 18: 1 \mathrm{n} 9$ in sum with the 


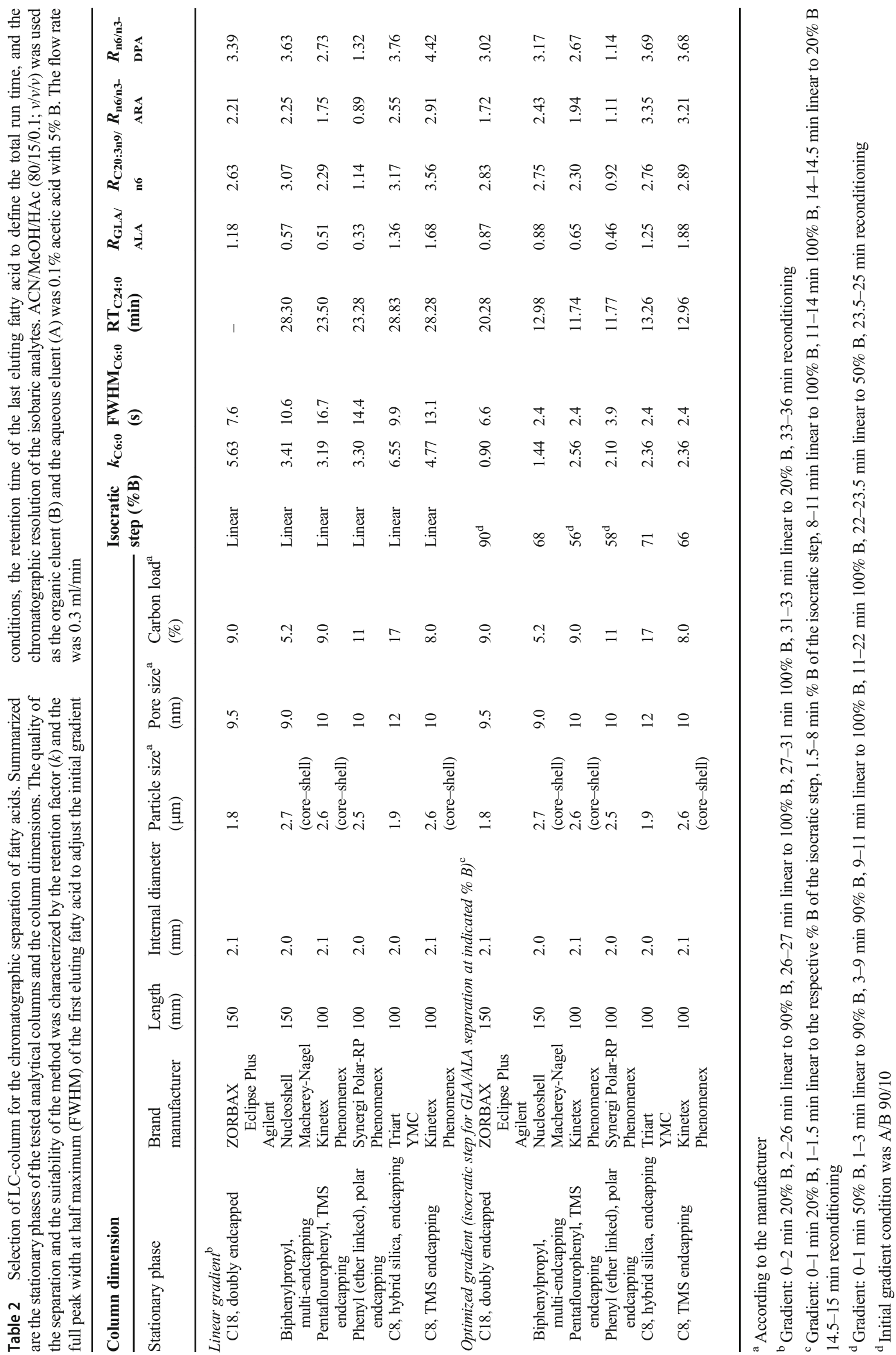


(a)

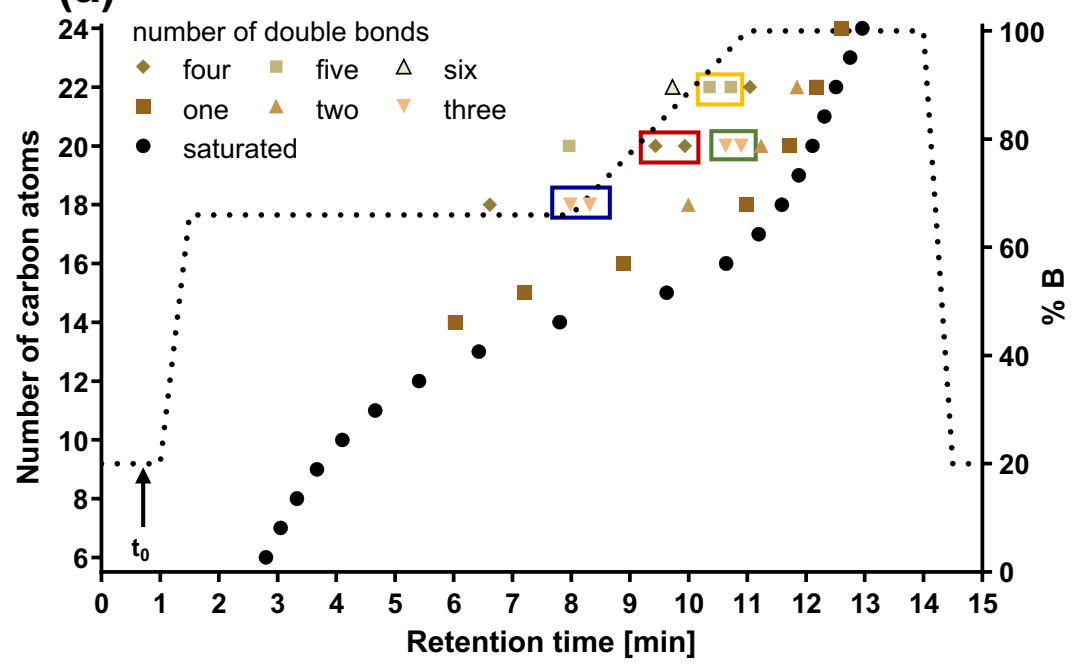

(b)
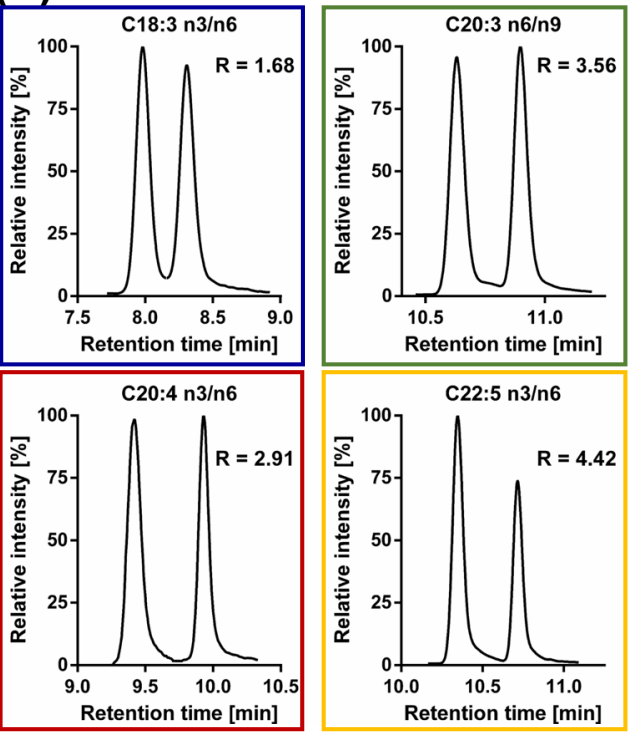

Fig. 2 a Relationship between retention time of the fatty acids and the number of carbon atoms as well as double bounds. b Chromatographic separation for isomeric fatty acids. Separation was carried out on an RP-8

respective isomer does not seem problematic for a correct determination of the quantitative fatty acid pattern in cells, blood, tissues and the most edible oils.

The method described herein is superior compared to previous LC-MS approaches. It requires no derivatization as used by several other groups $[14,15,23,24]$, which shortens sample preparation considerably. The total run time of $15 \mathrm{~min}$ allows rapid analysis. Even though a run time of around $15 \mathrm{~min}$ is also achieved in other methods, these methods quantify a considerably lower number of analytes ( 23 fatty acids [25], 14 fatty acids [14], 30 fatty acids [22]).

\section{Sensitivity}

The limit of detection (LOD) and lower limit of quantification (LLOQ) was determined according to the Guideline on Bioanalytical Method Validation of the European Medicines Agency (EMA) [30]. The LOD was set to the lowest injected standard yielding a signal-to-noise ratio $(\mathrm{S} / \mathrm{N})$ of $\geq 3$ and the LLOQ was set to the lowest standard yielding a signal-tonoise ratio of $\geq 5$ and an accuracy of $80-120 \%$ within the calibration curve. The LODs of the fatty acids detected by pseudo-SRM ranged mainly between 5 and $25 \mathrm{nM}(0.01-$ $0.08 \mathrm{ng}$ on column; Table 1), whereas the LODs for the transition based on decarboxylation were higher $(25-50 \mathrm{nM}$; $0.08-0.2 \mathrm{ng}$ on column) due to the low intensity of the $[\mathrm{M}-\mathrm{H}-44]^{-}$fragment. Therefore, fatty acids bearing $\geq 4$ double bounds were also quantified in pseudo-SRM mode. The sensitivity is consistent with earlier reported LODs, e.g., $0.02-$ $0.1 \mu \mathrm{M}(0.05-0.32 \mathrm{ng}$ on column) [25] and 0.03-0.3 $\mu \mathrm{M}$ (0.1-1 ng on column) [22]. It should be noted that we used a

column $(2.1 \times 100 \mathrm{~mm}, 2.6 \mu \mathrm{m}$ core-shell particle, pore size $10 \mathrm{~nm})$ with (a) a $\mathrm{H}_{2} \mathrm{O} / \mathrm{ACN} / \mathrm{MeOH} / \mathrm{HAc}$ gradient with a flow rate of $0.3 \mathrm{ml} / \mathrm{min}$. The void volume was approx. $0.24 \mathrm{ml}(0.8 \mathrm{~min})$

20-year-old middle class mass spectrometer. With state-ofthe-art high-resolution MS instruments such as LTQ Orbitrap Elite [16] or highly sensitive QqQ MS QTRAP 5500 [20], LODs of 1-2 orders of magnitude lower can be achieved.

The group of Hu et al. found a low LOD also for C16:0 and C18:0 (0.05 ng/ml; $0.20 \mathrm{nM}$ and $0.18 \mathrm{nM}$, respectively) [20]. In our hands, blank injections and even LC-MS measurements without injection also showed peaks for C16:0 and C18:0 (ESM Figs. S4 and S5) which could not be completely reduced by using pure solvents, glassware instead of plastic and methanol as well as iso-propanol for washing the injection system between runs. High background signals of these fatty acids - used ubiquitously in consumer products such as plastic ware-were also described by other groups $[18,23]$. For these analytes, we set the LLOQ to the concentration yielding a peak height of at least twofold of the peak height in blank injections and an accuracy within the calibration curve of 80 $120 \%$ (Table 1) which was $0.5 \mu \mathrm{M}$ for $\mathrm{C} 16: 0$ and $1 \mu \mathrm{M}$ for C18:0. The ULOQ was set to $20 \mu \mathrm{M}$. By using a deuterated internal standard for each of these compounds (C16:0-d4 and $\mathrm{C} 18: 0-\mathrm{d} 5)$ ion suppression occurring at this high concentration could be compensated allowing a linear regression. (ESM Figs. S4 and S6). In order to enable simultaneous quantification of C18:1 n9, which is a main FA in biological samples, quadratic least square regression (weighting: $1 / x^{2}$ ) was used. Only low carry-over was observed in the preceding injection of a high-concentrated standard (ESM Fig. S5). For quantification of all other fatty acids, linear calibration up to $2.5 \mu \mathrm{M}$ was used. This strategy using fatty acid-specific concentration ranges of the calibration series (Table 1) allows the rapid 
Fig. 3 Effect of pre-concentration step in the gradient on peak shapes of the first eluting fatty acids. Shown are injections $(10 \mu \mathrm{l})$ of a fatty acid standard $(0.5 \mu \mathrm{M})$ in ethanol at different initial gradient conditions. The initial conditions were held for $1 \mathrm{~min}$, then the $\% \mathrm{~B}$ was increased to $66 \% \mathrm{~B}$ in $0.5 \mathrm{~min}$
C6:0 20\% B

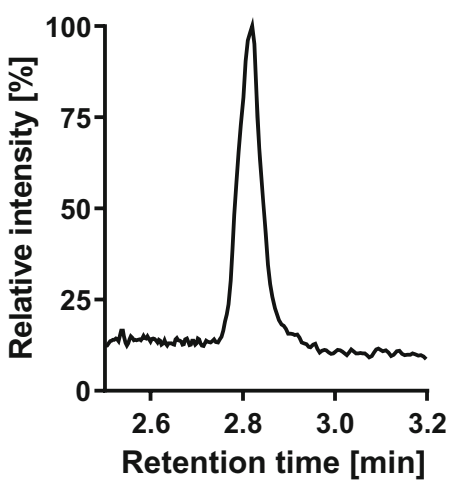

C7:0 20\% B

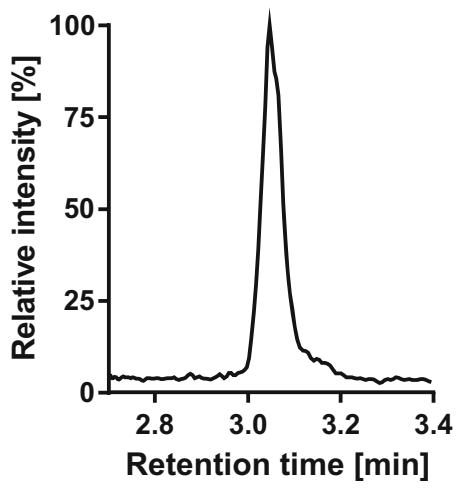

C6:0 $30 \%$ B

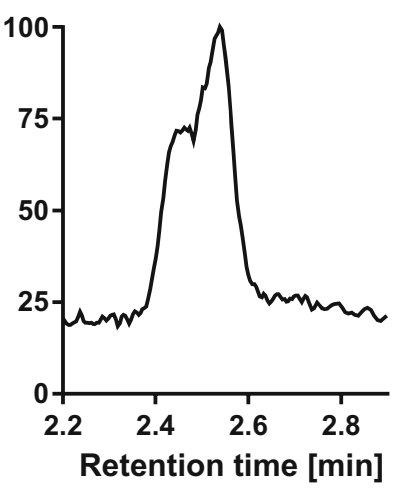

C7:0 $30 \%$ B

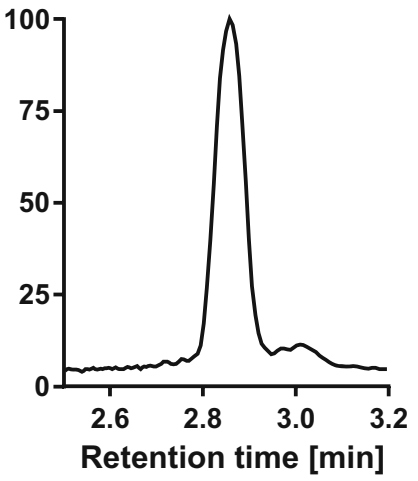

C6:0 40\% B

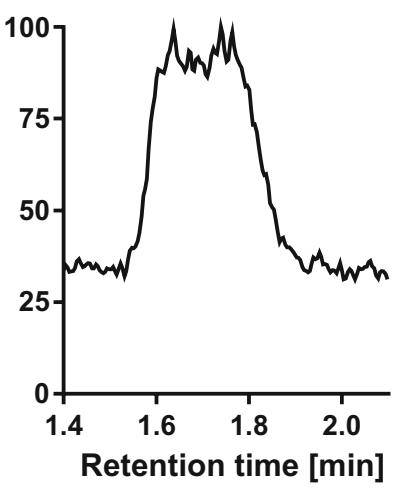

C7:0 40\% B

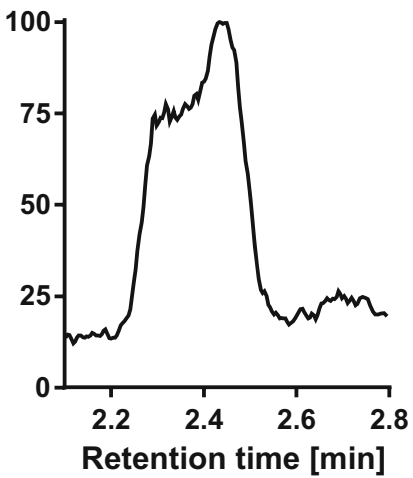

quantification of fatty acids in biological samples with only one set of calibrators. Due to the use of a large number of isotopically labeled IS, the analysis is also robust and shows high accuracy and precision.

\section{Accuracy and precision}

The accuracy of the developed analytical LC-MS method was assessed by comparing the fatty acyl concentrations in plasma and plant oils with those obtained by a validated GC-FID analysis (Fig. 4) which can be considered the gold standard of fatty acid analysis. The use of GC-FID provides an orthogonal quantification which is not dependent on standard concentrations due to the mass-sensitive detector allowing to deduce absolute concentration based on one reference compound. Sample preparation for gas chromatographic determination included lipid extraction with methanol/methyl tertbutyl ether (MTBE) and transesterification to FAME [12], whereas for LC analysis, the samples were diluted with isopropanol and the supernatant after centrifugation was directly hydrolyzed (Fig. 4a) [31]. The major fatty acyls quantified in the plasma were C16:0, C18:2 n6, and C18:1 n9+ n7, followed by $\mathrm{C} 18: 0$ and $\mathrm{C} 20: 4 \mathrm{n} 6$ as previously described for healthy subjects [7, 32]. The main n3-PUFA were ALA, EPA, and
DHA having concentrations of around $150 \mu \mathrm{M}$ (Fig. 4b). Given the difference in sample preparation, both methods showed an excellent match of the determined concentrations (agreement 80-120\%, Fig. 4b). Only for C18:0, slightly higher concentrations are obtained by means of LC-MS, presumably because of its high background signal. Differently diluted hydrolyzed plasma samples show that the matrix leads only to low or no ion suppression allowing robust quantification of the fatty acyls in biological samples (ESM Fig. S7).

In plant oils, similar levels of fatty acyls were found following quantification by means of GC-FID or LC-MS (Fig. $4 \mathrm{c}, \mathrm{d})$. For the main fatty acyls in flaxseed oil or sunflower oil, the concentration agreement was also good (70-130\%, Fig. $4 \mathrm{c}, \mathrm{d})$. Therefore, we conclude that the simple sample preparation by dilution with iso-propanol and saponification is suitable for the quantification of fatty acyls in protein-rich matrices as well as in fatty matrices. It should be noted that more fatty acids could be quantified by LC-MS than by GC-FID due to the higher sensitivity of the LC-MS method. The LLOQ of the LC-MS measurement is $\leq 75 \mathrm{nM}$ for almost all fatty acids, whereas it is more than one order of magnitude higher for the GC-FID analysis. This made it possible to quantify for example C22:5 n6 in plasma or C22:1 n9 in flaxseed oil allowing to gain a more comprehensive picture of the fatty 
(a)

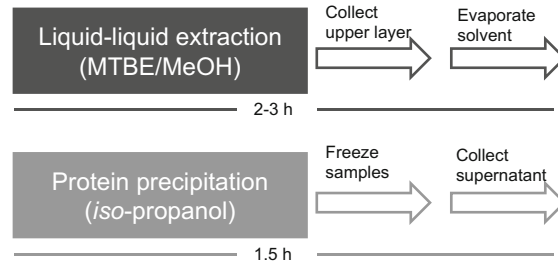

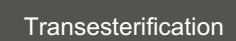

(meth. $\mathrm{HCl}$ )

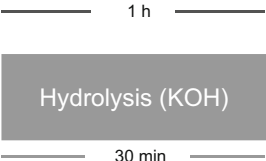

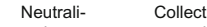

zation

zation $\longrightarrow$

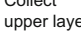

upper layer

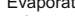

solvent
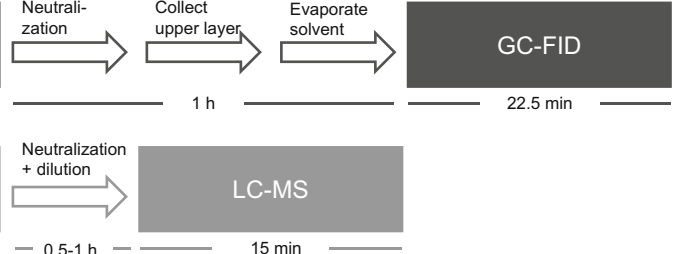

(b)
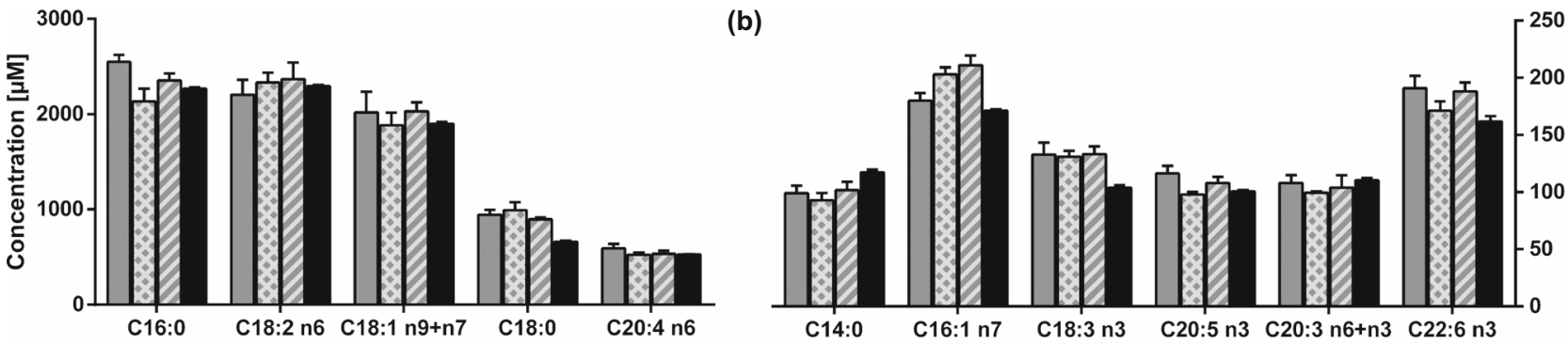

C14:0

C16:1 n7

(d)

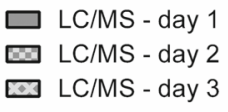

\section{0}

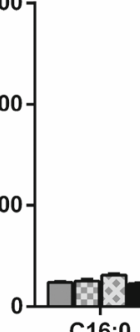

- GC-FID

plasma, $\mathbf{c}$ sunflower oil, and $\mathbf{d}$ flaxseed oil determined on 3 days by means of LC-MS (mean $\pm \mathrm{SD}, n=3$ ) compared to the concentrations determined by means of GC-FID (mean $\pm \mathrm{SD}, n=3$ )

results using transitions based on decarboxylation resulted in higher RSD, e.g., $15 \%$ for $\mathrm{C} 22: 5 \mathrm{n} 3$ vs. $5 \%$ in pseudo-SRM, which might be explained by low intensity of the [M-H-44] fragment and thus low peak heights. Therefore, quantification should be carried out by pseudo-SRM mode and the second transition can additionally be used for confirmation.

The determination of fatty acyls by LC-MS offers a much faster and more sensitive method than GC-FID analysis. We could show that the method leads to consistent and precise results. The easy and rapid sample preparation via direct saponification in iso-propanol is not only fast but allows the simultaneous total oxylipin determination (ESM Table S2) [31]. Thus, our approach makes it possible to analyze both oxidized fatty acyls and their precursors from a single sample preparation.

\section{Non-esterified fatty acids in plasma and edible oils}

Concentrations of NEFA were determined in plasma (ESM Table S3) and virgin, cold-pressed sunflower oil as well as refined sunflower oil (Fig. 5) using the described LC-MS method. In plasma, NEFA could be directly analyzed after 
Fig. 5 Concentration of nonesterified fatty acids in virgin and refined sunflower oil determined by LC-MS; 10 mg sunflower oil were dissolved in chloroform/isopropanol $(2 / 1, v / v)$ and triacylglycerols were removed by solidcartridges [13]. Refined and virgin oils were obtained from a lotriplicate $($ mean $\pm \mathrm{SD})$ phase extraction on aminopropyl cal supermarket and analyzed in

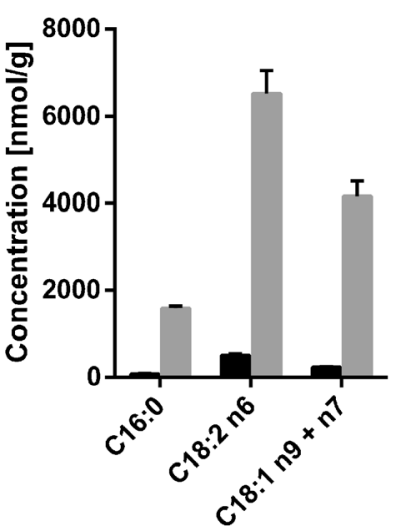

dilution of the sample with iso-propanol. The obtained concentrations (ESM Table S3) were in good agreement with the results described by other groups $[16,17]$. The accuracy of the measurement was supported by the standard addition procedure using ARA resulting in a concentration of $2.0 \mu \mathrm{M}$ in plasma, compared to $2.1 \pm 0.1 \mu \mathrm{M}$ by external calibration (ESM Fig. S8). This underlines the robustness of the method against matrix effects and demonstrates that the method allows the reliable quantification of three parameters from a single sample preparation: quantification of fatty acyls, NEFA and total oxylipins.

For quantification of NEFA in plant oils, the excess of triacylglycerols was reduced by SPE using aminopropyl cartridges as described $[13,34]$. As expected, the concentrations of NEFA were considerably lower in refined sunflower oil than in virgin sunflower oil, since the NEFA are removed in the deacidification step of the refining process [35]. C18:2 $\mathrm{n} 6$ was the fatty acid with the highest concentration, followed by $\mathrm{C} 18: 1 \mathrm{n} 9+\mathrm{n} 7, \mathrm{C} 16: 0$, and C18:0. Thus, the concentrations of NEFA represent the total fatty acid distribution (Fig. 4c). Because of the sensitivity of the method, we could detect low-concentrated fatty acids such as C22:1 n9, which often could not be reported [36, 37]. Due to the direct analysis of the NEFA by LC-MS, our method does not require derivatization for gas chromatographic analysis compared to previous methods, where different derivatization strategies such as esterification [38], silylation [36] or dimethylamidation [39] are used. The targeted approach allows quantification of NEFA even in the presence of triacylglycerols that may not have been completely removed by the SPE. Thus, the presented LC-MS method herein allows the reliable quantification of NEFA in biological samples, which is of pivotal importance for the characterization of both edible oils [35, 40] as well as biological samples such as plasma $[2,41]$.

\section{Conclusion}

A new LC-MS method for the quantification of fatty acids in biological samples was developed. Using an optimized C8 reversed phase column, 41 fatty acids and 11 isotopically
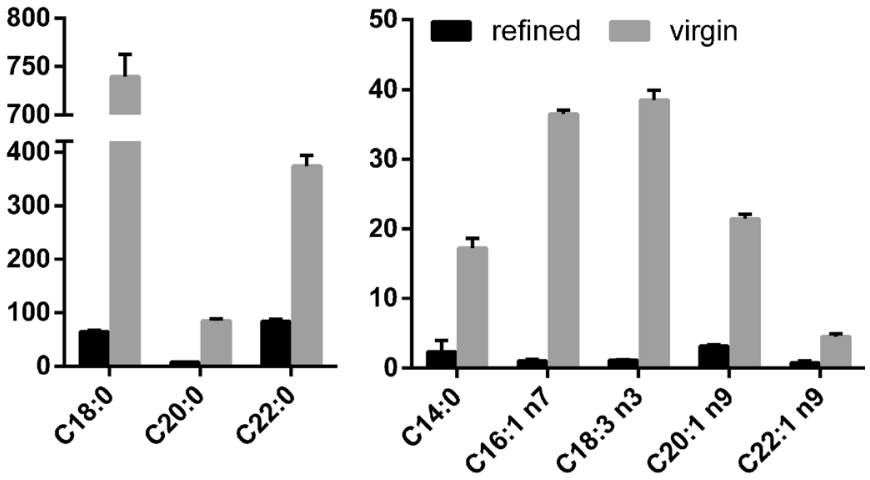

labeled fatty acids as internal standards could be separated within a total run time of only $15 \mathrm{~min}$. Despite using a rather old, middle class QqQ MS, the method is sensitive with a LLOQ of 10-75 nM for most fatty acids. The low inter-day and inter-operator variability of $<20 \%$ indicates a high precision of the method. The concentrations of fatty acyls determined by LC-MS in plasma and plant oils are consistent with those of a gas chromatographic analysis ensuring accurate and comparable results by the developed method. A major strength of the approach is the rapid sample preparation by hydrolysis and dilution allowing high sample throughput. Moreover, the analysis can be combined with the analysis of PUFA oxidation products (eicosanoids and other oxylipins) [31]. Finally, LC-MS analysis allows to quantify NEFA in presence of triacylglycerols which is of pivotal importance for the analysis of biological samples such as plant oils.

Abbreviations ACN, Acetonitrile; ALA, $\alpha$-Linolenic acid; ARA , Arachidonic acid; BHT, Butylated hydroxy toluene; CID, Collision-induced dissociation; DGLA, Dihomo- $\gamma$-linolenic acid; DHA, Docosahexaenoic acid; DPA, Docosapentaenoic acid; EPA, Eicosapentaenoic acid; EMA, European Medicines Agency; EtOH, Ethanol; FWHM, Full width at half maximum; FAME, Fatty acid methyl ester; GC-FID, Gas chromatography-flame ionization detection; GLA, $\gamma$ Linolenic acid; HAc, Acetic acid; IS, Internal standard; LA, Linoleic acid; LC-MS, Liquid chromatography-mass spectrometry; LOD, Limit of detection; LLOQ, Lower limit of quantification; $\mathrm{MeOH}$, Methanol; MTBE, Methyl tert-butyl ether; NEFA, Non-esterified fatty acid; PUFA, Polyunsaturated fatty acid; R, Resolution; RSD, Relative standard deviation; RT, Retention time; SPE, Solid phase extraction; SRM, Scheduled selected reaction monitoring

Acknowledgements This study was supported by a $\mathrm{PhD}$ fellowship of the Ev. Studienwerk Villigst e.V. to Elisabeth Koch. We would like to thank Michael Rothe (Lipidomix Berlin) for the helpful discussions.

Funding Open Access funding enabled and organized by Projekt DEAL.

\section{Declarations}

Ethics approval The collection of blood for plasma generation was approved by the Ethics Committee of the University of Wuppertal and an informed consent was obtained from all human subjects. 
Conflict of interest The authors declare no competing interests.

Open Access This article is licensed under a Creative Commons Attribution 4.0 International License, which permits use, sharing, adaptation, distribution and reproduction in any medium or format, as long as you give appropriate credit to the original author(s) and the source, provide a link to the Creative Commons licence, and indicate if changes were made. The images or other third party material in this article are included in the article's Creative Commons licence, unless indicated otherwise in a credit line to the material. If material is not included in the article's Creative Commons licence and your intended use is not permitted by statutory regulation or exceeds the permitted use, you will need to obtain permission directly from the copyright holder. To view a copy of this licence, visit http://creativecommons.org/licenses/by/4.0/.

\section{References}

1. Calder PC. Mechanisms of action of (n-3) fatty acids. J Nutr. 2012;142(3):592-9.

2. Calder PC. Functional roles of fatty acids and their effects on human health. Jpen-Parenter Enter. 2015;39:18-32.

3. Quehenberger O, Dennis EA. The human plasma lipidome. New Engl J Med. 2011;365(19):1812-23.

4. Buczynski MW, Dumlao DS, Dennis EA. An integrated omics analysis of eicosanoid biology. J Lipid Res. 2009;50(6):1015-38.

5. Gabbs M, Leng S, Devassy JG, Monirujjaman M, Aukema HM. Advances in our understanding of oxylipins derived from dietary PUFAs. Adv Nutr. 2015;6(5):513-40.

6. Browning LM, Walker CG, Mander AP, West AL, Madden J, Gambell JM, et al. Incorporation of eicosapentaenoic and docosahexaenoic acids into lipid pools when given as supplements providing doses equivalent to typical intakes of oily fish. Am J Clin Nutr. 2012;96(4):748-58.

7. Schuchardt JP, Ostermann AI, Stork L, Kutzner L, Kohrs H, Greupner T, et al. Effects of docosahexaenoic acid supplementation on PUFA levels in red blood cells and plasma. Prostag Leukotr Ess. 2016;115:12-23.

8. Wood KE, Mantzioris E, Gibson RA, Ramsden CE, Muhlhausler BS. The effect of modifying dietary LA and ALA intakes on omega-3 long chain polyunsaturated fatty acid (n-3 LCPUFA) status in human adults: a systematic review and commentary. Prostag Leukotr Ess. 2015;95:47-55.

9. Thurnhofer S, Vetter W. A gas chromatography/electron ionization-mass spectrometry-selected ion monitoring method for determining the fatty acid pattern in food after formation of fatty acid methyl esters. J Agric Food Chem. 2005;53(23):8896-903.

10. Zhang LX, Li PW, Sun XM, Wang XF, Xu BC, Wang XP, et al. Classification and adulteration detection of vegetable oils based on fatty acid profiles. J Agric Food Chem. 2014;62(34):8745-51.

11. Zhu GT, Liu F, Li PY, He S, Zhu SK, Gao Q, et al. Profiling free fatty acids in edible oils via magnetic dispersive extraction and comprehensive two-dimensional gas chromatography-mass spectrometry. Food Chem. 2019;297.

12. Ostermann AI, Muller M, Willenberg I, Schebb NH. Determining the fatty acid composition in plasma and tissues as fatty acid methyl esters using gas chromatography - a comparison of different derivatization and extraction procedures. Prostag Leukotr Ess. 2014;91(6):235-41.

13. Kutzner L, Ostermann AI, Konrad T, Riegel D, Hellhake S, Schuchardt JP, et al. Lipid class specific quantitative analysis of n-3 polyunsaturated fatty acids in food supplements. J Agric Food Chem. 2017;65(1):139-47.
14. Li XN, Franke AA. Improved LC-MS method for the determination of fatty acids in red blood cells by LC-Orbitrap MS. Anal Chem. 2011;83(8):3192-8.

15. Tie C, Hu T, Zhang XX, Zhou J, Zhang JL. HPLC-MRM relative quantification analysis of fatty acids based on a novel derivatization strategy. Analyst. 2014;139(23):6154-9.

16. Christinat N, Morin-Rivron D, Masoodi M. High-throughput quantitative lipidomics analysis of nonesterified fatty acids in human plasma. J Proteome Res. 2016;15(7):2228-35.

17. Hellmuth C, Weber M, Koletzko B, Peissner W. Nonesterified fatty acid determination for functional lipidomics: comprehensive ultrahigh performance liquid chromatography-tandem mass spectrometry quantitation, qualification, and parameter prediction. Anal Chem. 2012;84(3):1483-90.

18. Schiesel S, Lammerhofer M, Lindner W. Quantitative LC-ESI-MS/ MS metabolic profiling method for fatty acids and lipophilic metabolites in fermentation broths from beta-lactam antibiotics production. Anal Bioanal Chem. 2010;397(1):147-60.

19. Dasilva G, Pazos M, Gallardo JM, Rodriguez I, Cela R, Medina I. Lipidomic analysis of polyunsaturated fatty acids and their oxygenated metabolites in plasma by solid-phase extraction followed by LC-MS. Anal Bioanal Chem. 2014;406(12):2827-39.

20. $\mathrm{Hu}$ T, An ZL, Shi C, Li PF, Liu LH. A sensitive and efficient method for simultaneous profiling of bile acids and fatty acids by UPLC-MS/MS. J Pharmaceut Biomed. 2020;178.

21. Bromke MA, Hochmuth A, Tohge T, Fernie AR, Giavalisco P, Burgos A, et al. Liquid chromatography high-resolution mass spectrometry for fatty acid profiling. Plant J. 2015;81(3):529-36.

22. Zehethofer N, Pinto DM, Volmer DA. Plasma free fatty acid profiling in a fish oil human intervention study using ultra-performance liquid chromatography/electrospray ionization tandem mass spectrometry. Rapid Commun Mass Sp. 2008;22(13):2125-33.

23. Volpato M, Spencer JA, Race AD, Munarini A, Belluzzi A, Cockbain AJ, et al. A liquid chromatography-tandem mass spectrometry method to measure fatty acids in biological samples. J Chromatogr B. 2017;1055:125-34.

24. Williams J, Pandarinathan L, Wood J, Vouros P, Makriyannis A. Endocannabinoid metabolomics: a novel liquid chromatographymass spectrometry reagent for fatty acid analysis. AAPS J. 2006;8(4):E655-E60.

25. Chen L, Xie BY, Li L, Jiang WZ, Zhang Y, Fu J, et al. Rapid and sensitive LC-MS/MS analysis of fatty acids in clinical samples. Chromatographia. 2014;77(17-18):1241-7.

26. Koch E, Mainka M, Dalle C, Ostermann AI, Rund KM, Kutzner L, et al. Stability of oxylipins during plasma generation and long-term storage. Talanta. 2020;217.

27. Solis MIV, Patel A, Orsat V, Singh J, Lefsrud M. Fatty acid profiling of the seed oils of some varieties of field peas (Pisum sativum) by RP-LC/ESI-MS/MS: towards the development of an oilseed pea. Food Chem. 2013;139(1-4):986-93.

28. Rund KM, Ostermann AI, Kutzner L, Galano JM, Oger C, Vigor C, et al. Development of an LC-ESI(-)-MS/MS method for the simultaneous quantification of 35 isoprostanes and isofurans derived from the major n3- and n6-PUFAs. Anal Chim Acta. 2018;1037: 63-74.

29. Greupner T, Kutzner L, Pagenkopf S, Kohrs H, Hahn A, Schebb $\mathrm{NH}$, et al. Effects of a low and a high dietary LA/ALA ratio on longchain PUFA concentrations in red blood cells. Food Funct. 2018;9(9):4742-54.

30. European Medicines Agency. Guideline on bioanalytical method validation. 2011;EMEA/CHMP/EWP/192217/2009 Rev. 1 Corr. 2.

31. Ostermann AI, Koch E, Rund KM, Kutzner L, Mainka M, Schebb NH. Targeting esterified oxylipins by LC-MS - effect of sample preparation on oxylipin pattern. Prostag Oth Lipid M. 2020;146.

32. Lepage G, Roy CC. Direct transesterification of all classes of lipids in a one-step reaction. J Lipid Res. 1986;27(1):114-20. 
33. Lisa M, Netusilova K, Franek L, Dvorakova H, Vrkoslav V, Holcapek M. Characterization of fatty acid and triacylglycerol composition in animal fats using silver-ion and non-aqueous reversedphase high-performance liquid chromatography/mass spectrometry and gas chromatography/flame ionization detection. J Chromatogr A. 2011;1218(42):7499-510.

34. Lacaze JPCL, Stobo LA, Turrell EA, Quilliam MA. Solid-phase extraction and liquid chromatography-mass spectrometry for the determination of free fatty acids in shellfish. J Chromatogr A. 2007:1145(1-2):51-7.

35. Bhosle BM, Subramanian R. New approaches in deacidification of edible oils - a review. J Food Eng. 2005;69(4):481-94.

36. Wan PJ, Dowd MK, Thomas AE, Butler BH. Trimethylsilyl derivatization/gas chromatography as a method to determine the free fatty acid content of vegetable oils. J Am Oil Chem Soc. 2007;84(8):701-8.

37. Wei F, Zhao Q, Lv X, Dong XY, Feng YQ, Chen H. Rapid magnetic solid-phase extraction based on monodisperse magnetic single-crystal ferrite nanoparticles for the determination of free fatty acid content in edible oils. J Agric Food Chem. 2013;61(1):76-83.

38. Kail BW, Link DD, Morreale BD. Determination of free fatty acids and triglycerides by gas chromatography using selective esterification reactions. J Chromatogr Sci. 2012;50(10):934-9.

39. Ichihara K, Kohsaka C, Yamamoto Y, Masumura T. Simultaneous determination of free fatty acids and esterified fatty acids in rice oil by gas chromatography. J Am Oil Chem Soc. 2021;98(2):149-55.

40. Frega N, Mozzon M, Lercker G. Effects of free fatty acids on oxidative stability of vegetable oil. J Am Oil Chem Soc. 1999;76(3):325-9.

41. Kahn SE, Hull RL, Utzschneider KM. Mechanisms linking obesity to insulin resistance and type 2 diabetes. Nature. 2006;444(7121): 840-6.

Publisher's note Springer Nature remains neutral with regard to jurisdictional claims in published maps and institutional affiliations. 